
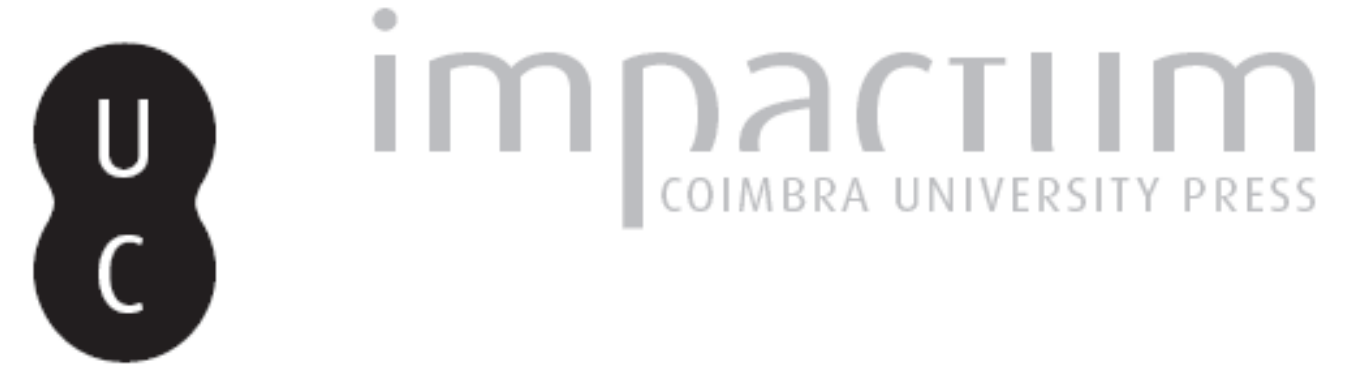

\title{
Fiscalidad Concejil y Administración del agua en la Castilla del Siglo XV
}

\author{
Autor(es): $\quad$ Val Valdivieso, Maria Isabel Del
}
Publicado por: Faculdade de Letras da Universidade de Coimbra, Instituto de História Económica e Social

URL persistente:

URI:http://hdl.handle.net/10316.2/29865

DOI:

DOI:http://dx.doi.org/10.14195/0870-4147_43_5

Accessed : $\quad$ 26-Apr-2023 10:53:36

A navegação consulta e descarregamento dos títulos inseridos nas Bibliotecas Digitais UC Digitalis, UC Pombalina e UC Impactum, pressupõem a aceitação plena e sem reservas dos Termos e Condições de Uso destas Bibliotecas Digitais, disponíveis em https://digitalis.uc.pt/pt-pt/termos.

Conforme exposto nos referidos Termos e Condições de Uso, o descarregamento de títulos de acesso restrito requer uma licença válida de autorização devendo o utilizador aceder ao(s) documento(s) a partir de um endereço de IP da instituição detentora da supramencionada licença.

Ao utilizador é apenas permitido o descarregamento para uso pessoal, pelo que o emprego do(s) título(s) descarregado(s) para outro fim, designadamente comercial, carece de autorização do respetivo autor ou editor da obra.

Na medida em que todas as obras da UC Digitalis se encontram protegidas pelo Código do Direito de Autor e Direitos Conexos e demais legislação aplicável, toda a cópia, parcial ou total, deste documento, nos casos em que é legalmente admitida, deverá conter ou fazer-se acompanhar por este aviso.

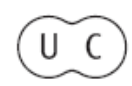





\title{
Fiscalidad Concejil y Administración del Agua en la Castilla del Siglo XV*
}

\author{
Maria Isabel Del Val Valdivieso \\ Universidad de Valladolid (España) \\ delval@fyl.uva.es
}

\section{Resumo:}

El artículo estudia el papel del agua en el marco de la fiscalidad concejil de la Corona de Castilla en el siglo XV, analizando el interés de los concejos por la administración de los recursos hídricos y de otros elementos relacionados con el agua. Parte de algunas consideraciones generales sobre la importancia creciente del agua para las ciudades del final de la Edad Media, presentando el interés de los reyes y de los concejos. Aquellos animan a sus concejos a realizar determinadas intervenciones, y estos solicitan autorización a los reyes cuando quieren realizar obras de reparación, acometida o equipamiento.

Se estudian los ingresos generados en los concejos por conceptos relacionados con el agua: tributos y multas, explotación de bienes de propios (molinos, baños, salinas, abrevaderos, alguna instalación industrial, etc.) y rentas diversas derivadas de su titularidad sobre cursos fluviales o aguas municipales. Se estudian luego los gastos en asuntos relativos al agua: aprovisionamiento, obras de acondicionamiento de muelles, construcción y mantenimiento de acequias y canales para riego y el uso de la energía hidráulica, puentes y otras infraestructuras, que interesan a la sociedad en su conjunto a la vez que favorecen al concejo y al núcleo urbano que las acomete, entre ellas algunas instalaciones artesanales como tintes y tenerías; y se atiende
Abstract:

The article examines the role of water in the framework of municipal taxation in the Crown of Castile in the $15^{\text {th }}$ century, by analyzing the interest of municipalities in the administration of water resources and other water-related items. It begins with some general considerations on the increasing importance of water for the cities in the end of the Middle Ages, then it presents the interests of kings and municipalities. Kings encouraged their municipalities to perform certain interventions, and the latter requested royal authorization when they wanted to carry out works of repair, connection or equipment.

Revenues generated in the municipalities by water-related items are studied: taxes and fines, exploitation of municipal assets (mills, baths, salinas, drinking troughs, some industrial premises, etc.) and several rents derived from their ownership over rivers or municipal waters. Then attention is paid to the expenses in matters relating to water: supply, works for the betterment of wharfs, construction and maintenance of ditches and canals for irrigation and use of hydropower, bridges and other infrastructure, that were of interest to the society as a whole as well as to the municipality and the urban nucleus that undertook them, including some artisanal tanneries and dyeing facilities; and also caters to which seems to be a frequent cause of

* El presente trabajo se ha realizado en el marco de los proyectos de investigación financiados por el Ministerio de Ciencia e Innovación HAR2008-01441 y por el Ministerio de Economía y Competitividad HAR2011-27016-C02-02. 
también a la que parece ser una frecuente causa de gasto, los pleitos. Esto enlaza con los conflictos que provoca la resistencia que a veces protagonizan quienes han de satisfacer los pagos que les corresponde, o bien por las diferencias de interés o de criterio que surgen en torno a cuestiones relativas al agua y las infraestructuras con ella relacionadas, siempre en el campo de la fiscalidad concejil.

Palavras chave:

Agua; Fiscalidad; Historia urbana; Castilla en la baja edad media; Concejos medievales. expenditure, the lawsuits. This ties in with conflicts caused sometimes by the resistance of those who had to meet compulsory payments, either by interest or criterion differences arising around issues about water and related infrastructure, always on the grounds of municipal taxation.

Keywords:

Water; Taxation; Urban history; Castile in the Late Middle Ages; Medieval municipalities. 


\section{Introducción}

Para abordar el tema propuesto se puede partir de tres preguntas que son necesarias para estudiar la fiscalidad concejil: quien paga y porqué, y sobre qué se establece la exacción fiscal. Por lo que respecta a este tercer aspecto, parece evidente que el fisco conecta directamente con la actividad económica, con la producción, distribución y comercialización de bienes ${ }^{1}$; eso nos puede conducir hasta una de las facetas del agua, aquella que hace referencia a su relación con las actividades económicas, tanto agropecuarias como artesanales y comerciales, lo que a su vez permite enlazar con la temática tributaria. Pero en el contexto de la hacienda concejil también hay que prestar atención a otros aspectos propios de este elemento, particularmente la importancia sociopolítica que el agua llega a alcanzar en la Edad Media. Todo esto nos lleva a constatar que al final de ese período el agua proporciona a los concejos ingresos por diferentes vías, a la vez que provoca gastos, derivados casi siempre de obras de infraestructura o de la defensa de los derechos que se pretende tener sobre ella.

En las investigaciones realizadas sobre fiscalidad y hacienda municipal, aparecen con bastante frecuencia algunos capítulos derivados directamente de las necesidades y/o problemas que la población urbana del siglo XV castellano tiene en relación con el agua, entendido este término en su sentido más amplio. No obstante, ese vital elemento, cuya presencia en villas y ciudades se hace cada vez más evidente y necesaria, no es contemplado por sí mismo, como habitualmente tampoco lo son otros asuntos y actividades que proporcionan ingresos fiscales a los concejos, o en los que éstos se ven obligados a gastar parte de sus recursos. Por esta razón, a partir de los datos aportados en los trabajos realizados por otros investigadores, así como de alguna noticia puntual de primera mano, dedicaré las páginas siguientes a una presentación del papel que el agua, y otros asuntos con ella relacionados, pudo tener en los capítulos de ingresos y gastos concejiles en la Castilla del final de la Edad Media.

Antes de abordar directamente el tema, es preciso llamar la atención sobre algunas cuestiones de carácter general. En primer lugar, la creciente presión social, representada en las ciudades y villas por la demanda de mayor comodidad y belleza, aboca a los concejos a ocuparse de acercar el agua a los consumidores, y a construir fuentes. Conseguir esos dos objetivos supone siempre la realización de elevados gastos, como puede verse en el caso de Valladolid; en 1500 esta

1 Miguel Ángel Ladero Quesada, El siglo XV en Castilla: fuentes de renta y política fiscal, Barcelona, 1982, p. 58. 
villa intenta, por segunda vez, llevar el agua hasta la plaza del mercado, por lo que solicita a los reyes el permiso necesario para proceder a la percepción de una sisa, que en 1501 se está cobrando; pero su fruto no es suficiente, por lo que tiene que recurrir a un préstamo de 90.000 maravedís facilitado por los mercaderes ${ }^{2}$. Otras veces se trata de obras de infraestructura. Ese es el caso de la construcción y reparo de los muelles marítimos, que los núcleos costeros tienen que acometer. Un ejemplo lo ofrece el concejo de Laredo que en 1497 lleva ya dos años ocupado en la tarea de construir un dique que preserve la villa, ya que un temporal ha destruido parte del muro y algunas torres; dado que sus recursos ordinarios no son suficientes para acometer la obra, ha cobrado durante ese tiempo, con permiso real, una sisa sobre el pescado, sal, vino, carne y trigo; en esa fecha solicita a los reyes poder percibir, durante los dos años siguientes, los "dos maravedís al millar" sobre las mercancías que se cargaran o descargaran en la villa, pues sin ello no consideran posible terminar la obra del cay ${ }^{3}$.

Pero el agua también puede proporcionar algunos ingresos. La preservación de la higiene y la seguridad supone la adopción de acuerdos y la imposición de determinadas normas, relacionadas con el uso del agua por parte de los vecinos en general y en particular de algunos oficios, cuyo no cumplimiento significa el pago de multas. Así lo estipulan las ordenanzas de Ávila de 1487, que multan con seis maravedís para el concejo o el arrendador a quienes laven lana o lino, en un tramo determinado del Adaja, "desde la pesquera del molino de la puente de Alonso Dávila arriba"; si esa actividad se realiza en las fuentes o pilones de la ciudad o de sus arrabales la multa es mucho mayor, ya que asciende a sesenta maravedís; esa misma cantidad tendrían que pagar aquellos que tomaran agua de esos mismos lugares para regar sus huertas o cultivos; igualmente castigan con penas pecuniarias a los pescaderos que derramen agua sucia en la calle ${ }^{4}$.

Por otro lado, las prerrogativas jurisdiccionales que los gobiernos urbanos tienen sobre su término, les permiten establecer cierto control sobre las corrientes fluviales y las aguas costeras, de lo que pueden derivarse ingresos por diferentes conceptos, especialmente peajes o multas; esto último podemos observarlo en el caso de Cuellar, cuyas ordenanzas de 1499 imponen una multa

$2 \mathrm{M}^{\mathrm{a}}$ Isabel del Val Valdivieso, "El abastecimiento de agua a Segovia en el contexto bajomedieval castellano", Estudios segovianos, XXXVII, 94, 1996, p. 736.

3 Virginia Cuñat Ciscar, Documentación medieval de la villa de Laredo, 1200-1500, Santander, 1998, doc. $\mathrm{n}^{\circ} 121$, p. 358-360.

4 José M Monsalvo Antón, Ordenanzas medievales de Ávila y su tierra, Ávila, 1990, p. 105 y 134 . 
de cincuenta maravedís a quienes pesquen en las pesqueras o cauces de los molinos del río Cega, salvo que lo hagan con anzuelo desde las pesqueras ${ }^{5}$.

Además, confiados en su autoridad, no faltan ocasiones en las que los concejos procuran extender su capacidad recaudatoria sobre espacios o personas que en puridad no están sometidos a su poder. Así se observa en la difícil relación que mantienen Portugalete y Bilbao, cuyos concejos pretenden controlar en beneficio propio la entrada de la ría, y percibir los correspondientes ingresos por el cobro de derechos de paso, carga y descarga ${ }^{6}$.

Por último, hay que señalar que la defensa de sus derechos y de las decisiones adoptadas lleva en ocasiones, cuando son contestadas, a tener que recurrir a la justicia, lo que supone un nuevo motivo de gasto, que a veces se afronta con la esperanza de conseguir, tras una sentencia favorable, el afianzamiento de una fuente de recursos para las arcas concejiles. Como ejemplo puede servir el pleito que enfrenta al concejo de Oñate con el monasterio de Santa María de Barría, que responde a las diferencias que hay entre ambos sobre el uso de pastos y agua para abrevar por parte del ganado monástico; o bien el que protagoniza Santa María del Puerto (Santoña), enfrentado con algunos vecinos de la cercana villa de Laredo, por el derecho de pesca ${ }^{7}$.

El agua, pues, hace acto de presencia en la hacienda concejil, tanto en el capítulo de ingresos como en el de gastos. Esto es lo que vamos a estudiar, sin olvidar la capacidad de intervención que al respecto se reserva la corona en los núcleos de realengo.

\section{La intervención real: de la recomendación a la autorización}

Como es bien conocido ${ }^{8}$, al final de la Edad Media en Castilla los núcleos urbanos cuentan con un sistema fiscal bien estructurado, que permite practicar, en beneficio de la colectividad o del interés público, la correspondiente

5 Emilio Olmos Herguedas, "El agua en la norma escrita. Una comparación de ordenanzas bajomedievales castellanas, en Cristina Segura (ed.), Agua y sistemas hidráulicos en la Edad Media hispana, Madrid, 2003, p. 42.

${ }_{6} \mathrm{M}^{\mathrm{a}}$ Isabel del Val Valdivieso, “Apuntes sobre el protagonismo del agua en el desarrollo de una villa vizcaína al final de la Edad Media”, en $\mathrm{M}^{\mathrm{a}}$ Isabel del Val Valdivieso, (coord.), Vivir del agua en las ciudades medievales, Valladolid, 2006, p. 73-97.

7 Archivo de la Real Chancillería de Valladolid (ARChV), Pleitos Civiles, Zarandona y Wals, depositados, C 1170-1 y 1171-1; ARChV, registro de Reales Ejecutorias (RRE), C 21-2.

8 Antonio Collantes de Terán y Denis Menjot, "Hacienda y fiscalidad concejiles en la Corona de Castilla en la Edad Media", Historia, Instituciones, Documentos, 23, 1996, p. 213-247. 
exacción obligatoria a todos los potenciales contribuyentes, bien fuera sobre la propiedad, el tránsito o el comercio. Se trata de un sistema, con su organización, normas y prácticas, en el que tiende a predominar el impuesto indirecto sobre el consumo; por lo tanto estamos ante un mecanismo que, al actuar más sobre lo que se consume que sobre la fortuna de cada contribuyente, favorece a los sectores dominantes en detrimento de aquellos que cuentan con menos recursos. Ahora bien, no es de este aspecto del que me voy a ocupar en esta ocasión, sino del papel que tiene el agua, y los derechos que sobre ella ejerce el regimiento, en la fiscalidad concejil.

Con el fin de atender a sus necesidades, los gobiernos urbanos podían imponer derramas o repartimientos, siempre que éstos no supusieran un gran volumen de recaudación. En el caso del realengo, cuando sobrepasaban los tres o cuatro mil maravedís se hacía preciso contar con la autorización regia9 . También era necesario tener el permiso de los monarcas para imponer sisas. De esta forma la monarquía disponía de una gran capacidad de intervención, ya que por esta vía no sólo conocía la situación de villas y ciudades en este terreno, sino que además podía controlar su actuación, haciendo posible o no, según su conveniencia y la correlación puntual de fuerzas, la puesta en práctica de algunas decisiones adoptadas por los regidores.

Por otra parte, la actitud de los reyes no se ciñe sólo a dar respuesta a una demanda. En ocasiones son ellos los que toman la iniciativa, sugiriendo, u ordenando, la realización de ciertas intervenciones, para las que hay que recurrir a destinar fondos que, o bien proceden de mercedes regias, o bien obligan a la imposición de tributos a la población, con el fin de lograr los recursos necesarios para poderlas llevar a la práctica. Así se constata en las últimas décadas del siglo XV, cuando los Reyes Católicos se encuentran al frente del reino castellano. Un ejemplo lo encontramos en Santo Domingo de la Calzada, cuyo corregidor es instado por los reyes, en 1495, para que realice las derramas necesarias en Cuzcurita de Riotirón y otros lugares, para poder proceder a edificar un puente sobre el Tirón; antes, en 1483, la ciudad había recibido de los reyes la exención de pedidos, monedas y servicios, con la condición de reparar, en el plazo de seis años, el puente sobre el Oja, con el fin

9 Evidentemente, en los casos de núcleos sometidos a la jurisdicción nobiliaria era preciso contar con la autorización del señor; así se observa en Palencia que precisa de la autorización del cabildo catedralicio. Hipólito Rafael Oliva Herrer, "Concejo, Cabildo y políticas del agua en Palencia a fines de la Edad Media", en $\mathrm{M}^{\mathrm{a}}$ Isabel del Val Valdivieso, (coord.), Vivir del agua en las ciudades medievales, p. 64. 
de favorecer el paso de los peregrinos ${ }^{10}$. Más adelante, cuando en noviembre de 1496 donan al concejo de Granada la cuarta parte de la renta de la hagüela, lo hacen para que la ciudad atienda al "reparo que aya menester", citando en particular las acequias, cuya importancia es evidente puesto que sólo en el caso de que sobrara algo después de atender estas necesidades podía destinarse a otros fines ${ }^{11}$.

Tener en cuenta esta circunstancia resulta fundamental para comprender la vida en los núcleos urbanos de esa época. Por un lado, a pesar de la autonomía alcanzada por los concejos, y de sus deseos de seguir avanzando en esa línea, la política de los reyes limita y controla su campo de actuación mediante un mecanismo que, a la vez que hace presente su poder por encima del que ostenta el concejo, les permite orientar hacia la dirección que les interesa la actuación de los poderes urbanos. Esto lo consiguen en parte a través del corregidor, cuyo protagonismo crece a lo largo de los últimos años de la decimoquinta centuria; así puede observarse en el concejo de Madrid donde, según establece una nueva ordenanza, el corregidor firma los libramientos junto con dos regidores, como lo hace en $1486^{12}$. Y lo logran también mediante esas decisiones a las que me acabo de referir, que afectan a la fiscalidad local en un doble sentido, aceptando o no la iniciativa concejil, e imponiendo a las ciudades algunas intervenciones concretas.

De esta forma la autoridad monárquica se hace patente para la mentalidad del conjunto social, lo que contribuye a dar cierta cohesión al reino, además de favorecer el orden y la paz en el mundo urbano ${ }^{13}$. En relación con lo que ahora nos interesa, los reyes pueden poner freno a una excesiva presión fiscal, limitando así las resistencias del vecindario a las exigencias del regimiento; y además contribuyen a favorecer la comodidad y belleza de la localidad, y con ello su honor y el de sus habitantes, mediante su respaldo a la realización de algunas obras que implican intervenir sobre los recursos

${ }^{10}$ Francisco Javier Goicolea Julián, "Finanzas concejiles en la Castilla Medieval: El ejemplo de la Rioja Alta (siglo XV-inicios del XVI)”, Brocar, 22, 1998, p. 39 nota 88.

11 Ángel Galán Sánchez y Rafael G. Peinado Santaella, "De la madina musulmana al concejo mudéjar. Fiscalidad regia y fiscalidad concejil en la ciudad de Granada tras la conquista castellana", en Denis Menjot y Manuel Sánchez Martínez, Fiscalidad de Estado y fiscalidad municipal en los reinos hispánicos medievales, Barcelona, 2006, p. 209-214.

${ }^{12} \mathrm{M}^{\mathrm{a}}$ de los Ángeles Monturiol González, "Estructura y evolución del gasto en la hacienda municipal de Madrid: último tercio del siglo XV”, En la España Medieval, 5, 1984, p. 662.

${ }^{13} \mathrm{M}^{\mathrm{a}}$ Isabel del Val Valdivieso, "Urban growth and royal interventionism in late medieval Castile", Urban History, 24, 1997, p. 129-140. 
hídricos y su disponibilidad. Así se observa en aquellos casos en los que, como en Portugalete, se autoriza la imposición de una sisa destinada a la realización de obras en la conducción y fuentes de la villa, una vez que se ha obtenido un informe favorable, que generalmente es solicitado al corregidor ${ }^{14}$.

\section{Ingresos}

Si nos fijamos en el capítulo de los ingresos, observamos que todos los concejos cuentan entre sus propios con bienes raíces, tierras e inmuebles, de los que obtienen parte de sus recursos, necesarios para mantener la administración, cumplir con sus obligaciones de gobierno, y atender a las demandas de los reyes o los vecinos. Entre esos propios pueden encontrarse algunas instalaciones relacionadas con el uso del agua, cuya renta contribuye a engrosar las arcas del concejo; sirva como ejemplo las pesqueras, que encontramos en Salamanca y otros muchos lugares. En ese concepto se incluyen además otras instalaciones como los baños, cuya integración en los propios concejiles se constata por ejemplo en Logroño ${ }^{15}$, aunque al final de la Edad Media su número se ha reducido ya claramente ${ }^{16}$. También las casas de los tintes y tenerías pueden reportar alguna renta, como se observa en Palencia, donde esas instalaciones pertenecen al concejo, quien las arrienda o cede a censo a los artesanos correspondientes ${ }^{17}$; y algo similar puede decirse de las barcas. En ocasiones tienen ferrerías que, como sucede con otros bienes de propios, se $\operatorname{arriendan}^{18}$.

${ }^{14}$ C. Hidalgo de Cisneros, E. Largacha, A. Lorente, A. Martínez, Colección documental del archivo municipal de Portugalete, San Sebastián, 1987, docs. nº 17 y 48, p. 63 y 221-230.

${ }^{15}$ Margarita Cantera Montenegro, "La hacienda concejil y la vida económica en Logroño en tiempos de los Reyes Católicos (1475-1495)", Anuario de Estudios Medievales, 17, 1987, p. 513.

${ }^{16}$ Magdalena Santo Tomás Pérez, Los baños públicos en Valladolid. Agua, higiene y salud en el Valladolid medieval, Valladolid, 2002.

${ }^{17}$ Asunción Esteban Recio, Palencia a fines de la Edad Media, Valladolid, 1989, p. 94-95. M Jesús Fuente Pérez, Finanzas y ciudades en el tránsito del siglo XV al XVI, Madrid, 1992, p. 85. Hipólito Rafael Oliva Herrer, "Concejo, Cabildo y políticas del agua en Palencia a fines de la Edad Media”, p. 59 y 62.

${ }^{18}$ La villa de Marquina adquiere en 1512, fruto de una donación testamentaria con una determinada carga de misas, la mitad de una ferrería y molino en Amollovieta, "desde la presa fasta el estolde"; al tomar posesión el representante del concejo recibe en sus manos "la bara del maço con su agua corriente"; ese mismo año el concejo arrienda la ferrería, comprometiéndose el arrendatario a pagar 24 quintales de hierro (J. Enríquez Fernández, Colección documental del archivo municipal de Marquina (1355-1516), San Sebastián, 1989, nº A43 y B15, p. 215 -216 y 331 . 
Pero son los molinos los que destacan claramente, en cuanto que es una propiedad con la que cuentan buena parte de los núcleos urbanos.

En líneas generales el rendimiento de las instalaciones molinares no parece ser muy elevado, aunque habría que considerar cada caso en particular, y atender además al número de ruedas y molinos con que contaba cada localidad; así Nájera, en 1476-77, obtiene por este concepto una renta de 220 fanegas de trigo (lo que representa el 56\% de los ingresos en grano), mientras que Haro nunca superó, a lo largo del siglo XV, las 60 fanegas, y cuando alcanzó esta cifra debió de ser por contar con dos molinos, ya que por el arriendo de 1467, que incluía "canales, rodete, muelas y hierros mayores", el arrendatario debía entregar 30 fanegas anuales ${ }^{19}$. Murcia, desde comienzos del siglo XV (1407-1408), percibe un censo de 2.400 maravedís por los "molinos del río", de los que 1.500 corresponden a los de la margen derecha del Segura, y 900 maravedís a los de la izquierda ${ }^{20}$.

En relación con el aprovechamiento ganadero, los concejos pueden disponer también de ingresos provenientes de sus abrevaderos y/o aljibes destinados a ese fin, como se constata en el caso de Murcia, que tiene cedidos a censo, en el Campo de Cartagena, los aljibes de Menado y La Higuera así como la Balsa $\mathrm{Blanca}^{21}$. Y también proporciona ingresos la cesión de agua para el riego como se observa en Madrid ${ }^{22}$.

Es relativamente frecuente el cobro de derechos de pesca, como lo hacen los concejos cantábricos de Pechón y Pesués, que perciben rentas de los ríos Deva y Nansa; por su parte, a comienzos del siglo XVI, Aranda de Duero arrienda la laguna de San Juan; mientras que el concejo de Ciudad Rodrigo arrienda el "piélago de la puente"; y los de Piedrahita y Ávila cobran las rentas del río ${ }^{23}$.

${ }^{19}$ Francisco Javier Goicolea Julián, "Finanzas concejiles en la Castilla Medieval: El ejemplo de la Rioja Alta", p. 26-27. Idem "Las finanzas concejiles y la fiscalidad de Nájera en la segunda mitad del siglo XV. El ejercicio del bolsero Martín Romerol (1476-1477)”, Espacio, Tiempo y Forma, 9, 1996, p. 123.

${ }^{20} \mathrm{M}^{\mathrm{a}}$ del Carmen Veas Arteseros, Fiscalidad concejil en la Murcia de fines del medievo, Murcia, 1991, p. 78. Denis Menjot, Fiscalidad y sociedad. Los murcianos y el impuesto en la Baja Edad Media, Murcia, 1986, p. 48.

${ }^{21} \mathrm{M}^{\mathrm{a}}$ del Carmen Veas Arteseros, Fiscalidad concejil en la Murcia de fines del medievo, p. 104.

${ }^{22}$ Eduardo Jiménez Rayado, El agua en el origen y desarrollo de Madrid en la Edad Media, Madrid, 2011, p. 193.

${ }^{23}$ Véase Isabel Abad García y Jesús Peribáñez Otero, "La pesca fluvial en el reino de Castilla

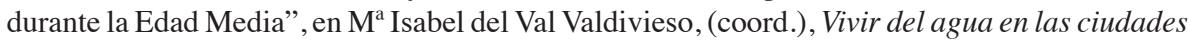
medievales, Valladolid, 2006, p. 174; y Juan Carlos Martín Cea, "La política municipal sobre el agua en los concejos de la Cuenca del Duero a fines de la Edad Media”, en Idem, p. 75. 
Además, en ocasiones, son titulares de salinas, de las que pueden obtener algunos maravedís. Murcia vuelve a ofrecernos un ejemplo claro, ya que la ciudad tiene entre sus propios, a fines del siglo XV, las de San Pedro del Pinatar y Sangonera; en 1471 obtiene de las primeras, por arrendamiento, unos 2.000 maravedís, mientras que en 1481 arrienda las segundas por 7.600 maravedís ${ }^{24}$. Pero no es el único caso en las tierras del Sur; entre otros puede recordarse la ciudad de Jaén, que las explota mediante arrendamiento cuyo fruto cobra en especie ${ }^{25}$; o bien la villa de Quesada que es titular de las de Salinas Rubias, Ausín, Rambla de Hernán García y Pozuelo ${ }^{26}$.

Los frutos obtenidos del ejercicio de ciertos derechos jurisdiccionales, que lo mismo que los propios suelen ser explotados mediante arrendamiento ${ }^{27}$, suponen otra vía de entrada de fondos a la hacienda local. Entre ellos están los establecidos sobre el agua, que permiten a los concejos obtener ciertos ingresos derivados de la cesión de uso de la misma para riego, de la pesca, o de la utilización de la energía hidráulica. Probablemente su rentabilidad contable no era grande, pero no hay que dejarla de lado. En el caso de la villa de Haro sabemos que el agua de riego suponía el 2'3\% de los ingresos totales, mientras que Nájera exigía ciertos pagos a Cenicero por pescar y por el uso del agua para $\operatorname{regar}^{28}$. Murcia percibe, a cambio de la cesión del uso del "agua de Mizatalla", un censo de un real de plata de cuño de Aragón; además consigue, como ya he indicado, algunos ingresos de los aljibes y abrevaderos ${ }^{29}$.

${ }^{24} \mathrm{M}^{\mathrm{a}}$ del Carmen Veas Arteseros, Fiscalidad concejil en la Murcia de fines del medievo, p. $161,167,168$ y 170 .

${ }^{25}$ En 1479 esa renta supone 2.500 fanegas de sal que se reparten entre los regidores y algunas otras personas, entre ellas caballeros, viudas de regidores y jurados, y la Iglesia. A. Castellano Gutiérrez, "Las salinas de Jaén: Contribución al estudio de la sal en la Andalucía medieval", Cuadernos de Estudios Medievales, VIII-IX, Granada, 1983, p. 159-163.

${ }^{26}$ Antonio Malpica Cuello, "Las salinas medievales del Alto Guadalquivir", Hispania, Al-Andalus, Castilla. Jornadas históricas del Alto Guadalquivir, Jaén, 1998, p. 288.

27 A. Romero Martínez, "Proceso recaudatorio y mecanismos fiscales en los concejos de la Corona de Castilla", Anuario de Estudios Medievales, 22, 1992, p. 750-752.

${ }^{28}$ Francisco Javier Goicolea Julián, "Finanzas concejiles en la Castilla Medieval: El ejemplo de la Rioja Alta", p. 50. Idem "Las finanzas concejiles y la fiscalidad de Nájera en la segunda mitad del siglo XV”, p. 125.

${ }^{29} \mathrm{M}^{\mathrm{a}}$ del Carmen Veas Arteseros, Fiscalidad concejil en la Murcia de fines del medievo, p. 106. 
Otra fuente de recursos para la hacienda concejil son las rentas que pueden obtenerse del tráfico y los intercambios. En relación con el segundo aspecto hay que fijarse en la renta del agua, que proviene del cobro de los tributos devengados por su acarreo y distribución, en función de los derechos que sobre la misma tiene el concejo, y de su capacidad para exigir gravámenes sobre el fruto del comercio de ese producto. En Madrid, por ejemplo, esta renta se arrienda, obteniendo con ello el concejo una cantidad que entre 1465 y 1497 oscila entre los 5.000 y 8.000 maravedís $^{30}$. Los libros de actas y las cuentas concejiles reflejan esta renta, de la que también hay noticia en Riaza, y en Palencia en $1474^{31}$. Años más adelante, en la relación del "valor de las rentas del año de" 1490 de Medina del Campo, se recoge su arrendamiento ${ }^{32}$; dos personas pugnan por quedarse con ella; en primer lugar Juan de Zamora, pescador, quien el día 11 de diciembre de 1489

por faser serviçio a los señores corregidor e regidores dixo que ponia e puso la renta del agua para el año venidero de noventa años en toda su aventura con las condiçiones e pagas del año pasado en nueve mil maravedis por una dobla de prometido si pujada le fuere, los quales dichos corregidor e regidores resçebieron la dicha postura e le otorgaron el dicho prometido ...

El día 19 de diciembre, ante el corregidor y varios regidores, el también vecino de Medina, Diego de Escalante pujó esa renta ofreciendo mil maravedís sin prometido. Ante esta situación, el 2 de enero de 1490, Zamora hace una nueva oferta; en esta ocasión

puso la dicha renta del agua para este año en dose mill maravedis por una dobla de prometido si pujada les fuere, ante el señor Ramir Nuñes de Gusman corregidor, e Pedro de Mercado e Alvaro de Lugo e Pedro de Sant Andres e Alonso Nieto, regidores, los quales resçibieron la dicha postura e le otorgaron la dicha dobla ...

${ }^{30} \mathrm{M}^{\mathrm{a}}$ de los Ángeles Monturiol González, "El ingreso en la hacienda municipal de Madrid: su estructura y evolución (1464-1497)", En la España Medieval, 7, 1985, p. 1032 y 1041.

${ }^{31}$ Hipólito Rafael Oliva Herrer, "Concejo, Cabildo y políticas del agua en Palencia a fines de la Edad Media", p. 57.

${ }^{32}$ Para los concejos este parece ser el sistema habitual de percepción de sus rentas; véase, Antonio Collantes de Terán Sánchez, "El sistema de arriendo de las rentas concejiles en las ciudades andaluzas en la baja edad media”, en Denis Menjot y Manuel Sánchez Martínez (Coords.), La fiscalité des villes au Moyen Âge (Occident méditerranéen). 4 La gestion de l'impôt, Toulouse, 2005, p. 204. 
Pero Diego de Escalante, dispuesto a quedarse con la renta del agua de Medina del Campo de 1490, el día 5 de enero puso "la dicha renta del agua en XIIIIU [14.000 mil] e un toro bueno o por el çien reales de plata"; de esta forma se queda con el arrendamiento, con la obligación de pagarlo por los tercios del año, y teniendo como fiador a su hijo Alvaro. En el cargo del mayordomo del concejo de ese año, Pedro Gutiérrez, se recoge así la situación:

"Mas se le carga aquí al dicho mayordomo la renta del agua de dicho conçejo de ques arrendador Diego Descalante e Alvaro Descalante su fiador con el de mancomun en la dicha renta e rematose en el por este dicho año de noventa en catorçe mil maravedis y mas un toro o por el çient reales, pagados por los terçios este dicho año y el toro quando ge le demandare el dicho conçejo al dicho mayordomo o por el los dichos çient reales, con las dos doblas que gano de prometido en la dicha renta Juan de Çamora pescador veçino de Medina" ${ }^{33}$.

En lo que se refiere al tránsito de personas, animales y mercancías el agua juega un papel relevante aunque indirecto en relación al cobro de tributos municipales. Las corrientes fluviales constituyen en ocasiones vías de comunicación y medio de transporte, pero en la red caminera castellana de la época que nos ocupa representan con más frecuencia un obstáculo a salvar. Las barcas y los puentes se hacen imprescindibles, incluso cuando hay vados, ya que éstos suelen quedar impracticables durante algunas temporadas, cuando crece el caudal y con ello la fuerza de las aguas. Unos y otras, puentes y barcas, pueden convertirse en fuente de rentas mediante el cobro por su uso, aunque también, como veremos en el lugar correspondiente, son objeto de gasto para el concejo.

En determinadas circunstancias los concejos consiguen el derecho al cobro del pontazgo, que les es cedido por el rey o señor del lugar, consiguiendo con ello una destacada fuente de renta. Así lo demuestran las cuentas de Haro, villa que recibió de su señora, Leonor de Alburquerque, el privilegio de poder cobrarlo; en el conjunto de ingresos concejiles este tributo resulta ser el más importante (representaba el 42,4\% del total) junto con la sisa del vino (34'4\%) a lo largo del siglo XV ${ }^{34}$. En el caso del concejo de Madrid, sabemos que cobraba

${ }_{33}$ Archivo Municipal de Medina del Campo, Libro de acuerdos de 1490, fols, 85 y 98.

${ }^{34}$ Leonor de Alburquerque, como señora de Haro, concedió a esta villa el pontazgo, y la escribanía de sacas, para que con su fruto pudiera pagar los gastos derivados del reparo de los puentes. Francisco Javier Goicolea Julián, "Finanzas concejiles en la Castilla Medieval: El ejemplo de la Rioja Alta", p. 28-29. 
derechos de paso de ganado por el puente de Viveros, sobre el Jarama, del que es titular ${ }^{35}$.

En los núcleos costeros se perciben también ingresos por el amarre, carga y descarga de los barcos. Un ejemplo claro lo ofrece Lequeitio, que cobra el nasaje a los navíos que llegan a su puerto, cuyo fruto comparte con el cabildo y cofradía de San Pedro; se trata de un ingreso que, al menos desde 1463, percibe mediante arrendamiento, y que destina fundamentalmente al mantenimiento del muelle y puerto; cuando ya a comienzo del siglo XVI (1511) la cantidad así recaudada no es suficiente para atender a esas obras, el concejo pretende imponer una sisa, pero ante la resistencia de los vecinos opta por elevar el nasaje durante dos años ${ }^{36}$.

Y no hay que olvidar las multas, parte de las cuales pueden recaer a favor del concejo. Para el tema que ahora nos ocupa hay diverso tipo de infracciones penadas con pagos en metálico, que suponen una fuente adicional de ingresos para la hacienda local, aunque por lo general suelen proporcionar una mínima parte de los mismos. Por un lado se encuentran las penas impuestas como consecuencia del mal uso del agua de riego, de haber provocado la contaminación del río, o de haber incumplido normas sobre la pesca. A esto hay que añadir las multas impuestas a quienes atentan contra el abastecimiento de agua, bien contaminando de alguna manera la destinada a consumo humano, bien reduciendo el caudal público disponible al apropiarse de ella indebidamente.

Con los ingresos provenientes de los propios, de la cesión de uso del agua, y de los impuestos sobre el tráfico y el comercio, complementados cuando es posible con el fruto de las multas, las villas y ciudades tienen que satisfacer, aunque no siempre lo consiguen, todos sus capítulos de gasto ordinario. Pero en la fiscalidad concejil castellana del final de la Edad Media, cuando es preciso atender a alguna necesidad de carácter extraordinario, se recurre habitualmente a otro tipo de impuestos. Entre ellos destacan los indirectos, particularmente las sisas, que resultan imprescindibles para dotar a los núcleos urbanos de nuevas instalaciones, entre las que se cuentan fuentes y puentes; para afrontar la reparación de algún inmueble, entre los que puede citarse a los molinos hidráulicos; o bien para mantener en buen estado algunas infraestructuras, como las canalizaciones o los muelles.

${ }^{35} \mathrm{M}^{\mathrm{a}}$ de los Ángeles Monturiol González, "Estructura y evolución del gasto en la hacienda municipal de Madrid: último tercio del siglo XV”, p. 681.

${ }^{36}$ Ernesto García Fernández, "Finanzas y fiscalidad de la villa de Lequeitio (1325-1516)", Anuarios de estudios medievales, 22, 1992, p. 719. 
Este tipo de impuesto se generalizó en los años finales del siglo XV, durante el reinado de los Reyes Católicos. Así puede observarse en el caso del concejo de Madrid, que a partir de la década de los '90 del siglo XV recurre a las sisas cada vez con mayor frecuencia ${ }^{37}$. Por citar un ejemplo puntual relacionado con el asunto que ahora nos interesa, se puede recordar que, en el año 1500, la ciudad de Oviedo logra el pertinente permiso real para cobrar una sisa cuyo fruto iría destinado, en parte, a reparar la fuente y construir un puente ${ }^{38}$. Unos años antes, en 1487, Avilés impone una sisa para reparar un puente, el de Pilares; al año siguiente los Reyes autorizan al concejo a imponer otra sisa para proceder a la necesaria reparación del cay ${ }^{39}$.

No obstante, en algunos casos se exigen exacciones directas para esas eventualidades; así sucede en la huerta de Murcia, donde, para atender a los reparos y limpieza periódica de las acequias, el concejo utiliza un sistema que mezcla el impuesto directo y el préstamo, y que afecta a todos los propietarios, incluido el clero ${ }^{40}$. Junto a esto, el préstamo exigido a los vecinos parece ser una solución relativamente habitual cuando la escasez de recursos es evidente, pues lo encontramos en numerosas localidades; ya me he referido al caso de Valladolid, al que puede sumarse el de Madrid, cuyo concejo recurre también en ocasiones a esa forma de obtener recursos ${ }^{41}$.

Pero en los casos de tributación extraordinaria directa lo más frecuente es el repartimiento, la distribución de la cantidad que se necesita entre los contribuyentes, bien de forma proporcional a su riqueza, o bien exigiendo una cantidad igual a cada uno de ellos, aunque en ninguno de los dos casos eso signifique que la carga fiscal que soporta cada vecino sea equitativa, pues la forma de establecer las pechas tiende a favorecer a quienes se encuentran situados en los escalones más elevados de la pirámide social ${ }^{42}$. Con todo, esta

${ }^{37} \mathrm{M}^{\mathrm{a}}$ de los Ángeles Monturiol González, "Estructura y evolución del gasto en la hacienda municipal de Madrid: último tercio del siglo XV", p. 663.

${ }^{38}$ Archivo General de Simancas (AGS), Registro General del Sello (RGS), 150005, fol. 548.

39 Jesús Á. Solórzano Telechea y Javier Añíbarro Rodríguez, "Infraestructuras e instalaciones portuarias, fluviales e hídricas en las villas del Norte peninsular a finales de la Edad Media: las obras públicas como instrumentos de poder", en $\mathrm{M}^{\mathrm{a}}$ Isabel del Val Valdivieso y Olatz Villanueva Zubizarreta, Musulmanes y cristianos frente al agua en las ciudades medievales, Santander, 2008, p. 278.

${ }^{40} \mathrm{M}^{\mathrm{a}}$ de los Llanos Martínez Carrillo, "La tabla murciana. Bases agrarias de una institución de crédito medieval”, Miscelánea Medieval Murciana, VIII, 1981, p. 31-54.

${ }^{41} \mathrm{M}^{\mathrm{a}}$ de los Ángeles Monturiol González, "Estructura y evolución del gasto en la hacienda municipal de Madrid: último tercio del siglo XV", p. 664.

${ }^{42}$ Hipólito Rafael Oliva Herrer, Ordenanzas de la villa de Becerril de Campos (c. 1492). Transcripción y estudio, Salamanca, 2003. 
forma de proceder suele provocar menos resistencias que la imposición de sisas, y se emplea también para asuntos relacionados con obras públicas, que en ocasiones afectan al uso del agua o a otras intervenciones con ella relacionadas, como los puentes. Así se puede constatar en la villa de Haro, que impone sendos pechos extraordinarios en 1465 y 1473 para atender al reparo del puente sobre el Ebro. Nájera recurre a igual sistema en el ejercicio 1475-1477, en el que reparte 10.678 maravedís que necesitaba para hacer arreglos en el puente ${ }^{43}$. Por su parte el concejo de Madrid, en 1483, estableció una derrama de 50.000 maravedís para sufragar los gastos de las obras en el puente de Toledo y en una pontezilla que está cerca de la huerta de Ferrando ${ }^{44}$.

\section{Gastos}

Es bien conocido que al final de la Edad Media se incrementan los motivos de gasto en todos los núcleos urbanos, como consecuencia de las nuevas demandas sociales, y de que crecen de forma notable las necesidades administrativas. Esto explica lo indicado hasta ahora, ya que al aumentar la necesidad de gasto, se intensifica la presión fiscal, dado que es necesario aumentar el volumen de lo recaudado.

Entre los capítulos de gasto que se hacen cada vez más abultados se cuentan los pleitos. Mantener estas acciones, hasta ver finalizado el juicio, que llega a veces hasta el tribunal de la Chancillería, supone cuantiosos gastos que obligan en ocasiones a recurrir a ingresos extraordinarios para poder defender hasta el final la postura concejil. Precisamente por eso, en 1495, Santo Domingo de la Calzada consigue autorización para recaudar mediante sisas los maravedís que necesita para pagar los gastos derivados de varios pleitos que mantenía en ese momento ${ }^{45}$. Entre los motivos de litigio no faltan los relacionados con el agua, bien sea el riego, el aprovechamiento de la energía hidráulica, los puentes o el tráfico; entre ellos se encuentra el conocido pleito que mantienen los concejos de Bilbao y Portugalete con motivo de la navegación por la ría, del que se conserva una carta ejecutoria solicitada por el bilbaíno en $1509^{46}$. También la pesca es causa recurrente de pleitos, entre los que se cuenta el que en la década

${ }^{43}$ Francisco Javier Goicolea Julián, "Finanzas concejiles en la Castilla Medieval: El ejemplo de la Rioja Alta", p. 35.

${ }^{44}$ Eduardo Jiménez Rayado, El agua en el origen y desarrollo de Madrid, p. 169.

${ }^{45}$ Francisco Javier Goicolea Julián, "Finanzas concejiles en la Castilla Medieval: El ejemplo de la Rioja Alta", p. 37.

${ }^{46}$ ARChV, RRE, caja 0235.0045. 
de los ' 30 del siglo XV mantuvieron los concejos del valle de Luna con el conde de Quiñones ${ }^{47}$. Y no faltan los incumplimientos de compromisos adquiridos, concretamente la satisfacción de la renta derivada del arrendamiento de algún propio concejil; eso es lo que lleva a Plencia a pleitear con dos vecinos de Bilbao herederos del arrendatario de un molino concejil, que no había pagado lo acordado con el concejo; en 1514, la carta ejecutoria dice que el asunto remonta a unos quince años atrás y condena a los bilbaínos al pago de la renta debida ${ }^{48}$.

La construcción o reparo de las fuentes, punto de abastecimiento vecinal en todos los casos, pero en ciertas ocasiones también motivo de embellecimiento y de orgullo local, supone otro de los capítulos de gasto que es necesario atender.

En general, una de las causas de incremento del gasto es, como ya he indicado, la realización de obras públicas, entre las que se cuentan las relacionadas con el agua. En ocasiones afrontar tales empresas supone un elevado grado de preocupación para el concejo, que es consciente de la conveniencia de hacer una fuerte inversión que le reportará beneficios, pero no siempre ingresos. Ante la falta de recursos para atender tales necesidades, hay ocasiones en las que incluso la Iglesia se ve afectada, debido a que el concejo, como hace el de Burgos, exige a sus miembros la contribución económica a tales obras ${ }^{49}$. E incluso hay ocasiones en las que al planificar los gastos se proyectan ya los posibles ingresos nuevos que se podrán obtener. Eso es lo que contempla el concejo de Aranda de Duero, cuando en los primeros años del siglo XVI se plantea desviar el cauce del río Aranzuelo ${ }^{50}$. Y eso mismo deben considerar las ciudades que tienen que ocuparse de algún puente, llegando incluso a utilizar parte de los ingresos obtenidos a partir de la obra terminada en el pago de los gastos derivados de su construcción; esto es lo que hace San Sebastián que pagó parte de la obra del puente de Urrusuno, sobre el Urumea, con el fruto del correspondiente pontazgo cobrado a personas y animales de carga ${ }^{51}$.

${ }^{47}$ Pablo García Cañón, "La pesca en los concejos de Luna de Yuso y de Luna de Suso (León) durante el siglo XV: luchas e intereses entre señores y pescadores", en Ma Isabel del Val Valdivieso, (coord.), Vivir del agua en las ciudades medievales, Valladolid, 2006, p. 197-198.

${ }^{48}$ J. Enríquez Fernández, Colección documental de la villa de Plencia (1299-1516), San Sebastián, 1988, docs. B 26, 27 y 28, p. 164-178.

${ }^{49}$ Denis Menjot, Dominar y controlar en Castilla en la Edad Media, Málaga, 2003, p. 151.

${ }^{50}$ Isabel Abad García y Jesús Peribáñez Otero, "El control social del agua en la villa de Aranda de Duero. El aprovechamiento del río Aranzuelo a principios del siglo XVI", en M ${ }^{a}$ Isabel del Val Valdivieso (coord.), Usos sociales del agua en las ciudades hispánicas de la Edad Media, Valladolid, 2002, p. 141-142.

${ }^{51}$ Ernesto García Fernández, "Finanzas municipales y fiscalidad real en el País Vasco en el tránsito del Medievo a la Modernidad”, en Denis Menjot y Manuel Sánchez Martinez, Fiscalidad de Estado y fiscalidad municipal en los reinos hispánicos medievales, Madrid, 2006, p. 184. 
Aunque proporcionan ingresos a través de la percepción del pontazgo, los puentes, su construcción y mantenimiento, son un motivo de casi constante inversión, debido a que mantenerlos en buen estado implica una permanente atención, puesto que es frecuente que sufran desperfectos como consecuencia de la acción del río, en especial cuando se producen crecidas. En esto, como en general en todo lo referente al mantenimiento de la estructura hídrica, los gastos que el agua genera superan los ingresos, tal y como se constata, por ejemplo, en Madrid ${ }^{52}$.

Volviendo al gasto que suponen los puentes, observamos que las noticias al respecto son abundantes. Entre ellas puede citarse de nuevo el caso de Haro, que emplea elevadas cantidades en las obras de reparo de los puentes; ya he indicado que precisamente con ese fin recibe de su señora el derecho a cobrar pontazgo; además en alguna ocasión, concretamente en 1464 y en 1476, tiene que recurrir a una derrama extraordinaria para reparar el puente sobre el río Tirón; sin embargo ese puente sigue sin resultar satisfactorio a fines de siglo, por lo que en 1498 el concejo solicita autorización a los reyes para poder obtener recursos extraordinarios, y en 1501 y 1503 realiza dos repartimientos de 224.060 maravedís cada uno para construir un puente nuevo. Algo similar sucede en otros lugares, como Logroño, que en la década de los '90 impuso una derrama a la villa de Matute para obtener fondos con los que reparar el puente $^{53}$. También Madrid ve cómo, a finales del siglo XV, se incrementan los gastos necesarios para promover el prestigio y la honra de la villa, contándose entre ellos las inversiones necesarias para mantener en buen estado sus tres puentes principales, los de Toledo, Segovia y Viveros; una muestra de ello son los 115.000 maravedís que gastan por ese concepto en $1489^{54}$.

Otras veces es necesario invertir en el reparo y mantenimiento de ciertas infraestructuras parte de los recursos obtenidos. Además de las instalaciones artesanales de las que en ocasiones es titular el concejo, hay que tomar en consideración la red de acequias allí donde existe. Junto al caso ya citado de la ciudad de Granada, uno de los ejemplos señeros es el de Murcia, cuyo concejo, para mantenerlas en buen estado, emplea importantes cantidades que obtiene

${ }^{52}$ Eduardo Jiménez Rayado, El agua en el origen y desarrollo de Madrid, p. 192.

${ }^{53}$ Franciso Javier Goicolea Julián, "Finanzas concejiles en la Castilla Medieval: El ejemplo de la Rioja Alta”, p. 34 (n. 61), 39 (n. 88) y 47 (n. 131).

${ }^{54} \mathrm{M}^{\mathrm{a}}$ de los Ángeles Monturiol González, "Estructura y evolución del gasto en la hacienda municipal de Madrid: último tercio del siglo XV", p. 681. J. A. Bonachía Hernando, "El agua

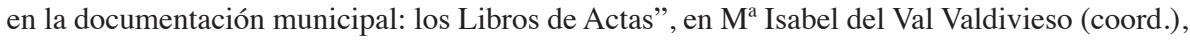
El agua en las ciudades castellanas durante la Edad Media. Fuentes para su estudio, Valladolid, 1998 , p. 55. 
fundamentalmente de las caloñas de la Huerta, que complementa con pequeños aportes obtenidos por otros conceptos, como los 210 maravedís que exige a los tintoreros por el uso que hacen de las acequias mayores ${ }^{55}$. En las villas costeras, las obras de los muelles suponen un importante capítulo de gasto, como puede constatarse en la ya citada villa de Laredo, que entre 1495 y 1502 consigue que los reyes le descuenten del encabezamiento de las alcabalas 610.000 maravedís (265.000 mrs. entre 1495-98, 213.000 mrs. en 1500 y 132.500 mrs. en 1502), para atender a esa necesaria inversión ${ }^{56}$.

Las obras de conducción del agua al interior de villas y ciudades son otro de los capítulos de las cuentas concejiles en los que se reflejan las inversiones que son necesarias para tener bien abastecida la ciudad. El caso más espectacular es sin duda el de Segovia, ya que se trata del famoso acueducto romano, que hubo de ser reparado en la segunda mitad del siglo XV. Las obras de restauración del cauce y de la madre del agua se alargaron hasta los primeros años del siglo XVI, y sirvieron para que la conducción siguiera abasteciendo de agua a la ciudad $^{57}$. Junto a esto también gastan los concejos en algunas infraestructuras relacionadas con el riego de sus campos, como se observa en el pago de Alcaná de la villa de Vera (Almería) donde el concejo gastó, en 1505, 23.000 maravedís procedentes de los bienes propios ${ }^{58}$.

Las fuentes constituyen otro capítulo de gasto, como lo demuestran las cuentas de Lequeitio de 1497, en las que se recoge que emplearon 3.000 maravedís en su reparo ${ }^{59}$. Y no hay que olvidar los molinos, dado que a pesar de que sus arrendatarios suelen estar obligados a mantenerlos en buen estado, los frecuentes desperfectos provocados por las crecidas obligan a intervenir al regimiento. Aunque las noticias son escasas y dispersas, también puede citarse algún caso particular, como el de Nájera, en cuyos libros de cuentas del ejercicio 1476-77 se consignan gastos en materiales y pagos a las personas que

${ }^{55} \mathrm{M}^{\mathrm{a}}$ del Carmen Veas Arteseros, Fiscalidad concejil en la Murcia de fines del medievo, p. 141-143, 200, 265-268.

${ }^{56}$ Miguel Ángel Ladero Quesada, "Las haciendas concejiles en la Corona de Castilla (Una visión de conjunto)", Finanzas y fiscalidad municipal. V Congreso de Estudios Medievales (León, 2-6 de diciembre de 1995), Ávila, 1997, p. 51.

${ }^{57} \mathrm{M}^{\mathrm{a}}$ Isabel del Val Valdivieso, "El abastecimiento de agua a Segovia", p. 740-742.

${ }^{58}$ Juan Francisco Jiménez Alcázar, “Agua, riego y repoblación en Vera (Almería) durante los siglos XV y XVI”, en M ${ }^{\mathrm{a}}$ Isabel del Val Valdivieso y Olatz Villanueva Zubizarreta, Musulmanes y cristianos frente al agua en las ciudades medievales, p. 405.

${ }^{59}$ Ernesto García Fernández, "Génesis y desarrollo de la fiscalidad concejil en el País Vasco durante la Edad Media (1140-1550)" en A. Furió (coord.), La gènesi de la fiscalitat municipal (segles XII-XIV), publicado en la Revista d'Historia Medieval, 7, 1996, p. 97. 
trabajaban en la reparación de los molinos ${ }^{60}$. En los primeros años del siglo XVI, concretamente en 1516, el concejo de Plencia, reunido a campana repicada en la iglesia de Santa María Magdalena, decidió imponer un repartimiento de 7.324 maravedís, con el fin de reparar los molinos "desta dicha villa que son en Yturbe", que se encontraban en mal estado debido a "la ronpydura que le avia fecho la mar brava", y lo hacen así por considerar que si no se arreglan esos desperfectos se arruinarían completamente ${ }^{61}$.

Además de reparar es preciso atender a obras de nueva planta, en especial "talleres" artesanales, puentes, molinos, o conducciones. En este último caso resalta la villa de Valladolid por las dificultades que retardaron el deseo concejil de llevar el agua hasta la plaza central de la localidad. El concejo no emprende la obra hasta 1494, encomendándosela a un ingeniero moro de Guadalajara; tres años después el agua ha llegado a una de las puertas, la del Campo, pero maestre Yuça no es capaz de hacerla avanzar hasta la plaza, donde ya se había construido una fuente; no sabemos el coste total de la obra, pero sí que los regidores dicen haberse gastado 750.000 maravedís, que reclaman a Yuça, demandado por incumplimiento de contrato, por lo tanto una elevada cantidad, a la que hay que sumar lo que costó después construir un lavadero cubierto en la puerta del Campo y el traslado a ese lugar de la fuente que se había levantado en la plaza mayor ${ }^{62}$.

Respecto a los molinos, destaca el caso de Oñate, que en 1488 decide construir dos nuevos, de una rueda cada uno, debido a que en su término no hay molinos suficientes para atender la demanda en época estival. Con ese fin suscribe un contrato con dos carpinteros que se encargarán de toda la obra (presa, canal, edificios, etc.). Según el documento suscrito, el concejo invertirá en esa obra, además de los solares y los materiales que puedan tomarse del monte comunal y de una dehesa (la de Balçola), 46.000 maravedís, de ellos diez mil al iniciarse la obra, otros tantos cuando se le acaben los diez mil primeros (a criterio de quien ha de controlar el proceso de construcción), y los 26.000 restantes cuando la obra sea recibida por el concejo ${ }^{63}$.

${ }^{60}$ Francisco Javier Goicolea Julián, "Finanzas concejiles en la Castilla Medieval: El ejemplo de la Rioja Alta", p. 40.

${ }^{61}$ J. Enríquez Fernández, Colección documental del archivo municipal de Marquina, doc. 31, p. 263-284.

${ }^{62}$ Fernando Pino Rebolledo, El primer libro de actas del Ayuntamiento de Valladolid. Año 1497, Valladolid, 1990, n 292 y 349, p. 117 y 134; Idem, Libro de actas del Ayuntamiento de Valladolid. Año 1498, Valladolid, 1992, nº 177, p. 168-170.

${ }^{63}$ I. Zumalde Igartúa, Colección documental del archivo municipal de Oñati (1149-1492), San Sebastián, 1994, doc. nº 33, p. 235-239. 
Por último hay que tener en cuenta ciertos salarios que se pagan a oficiales encargados de asuntos relacionados con el tema que nos ocupa. Entre ellos están los fontaneros encargados de las fuentes de la localidad, los acequieros, los alcaldes que se encargaban en Murcia de "las balsas, albercas, pozos et aljibes del campo de Cartagena" ${ }^{64}$, los poceros de Madrid, o los cañeros de Sevilla ${ }^{65}$, pero también aquellos que se ocupan de vigilar las costas o las aguas concejiles como los "alcaldes de la ribera" que se encuentran en los concejos castellanos, los "alcaldes de la nava" con que cuenta, entre otras villas, Becerril de Campos, o los albañaleros y fontaneros que se documentan en otros lugares ${ }^{66}$.

\section{Resistencias}

Ya he apuntado en los epígrafes anteriores que las exigencias fiscales de los concejos no son siempre bien recibidas. Sea porque los regidores se exceden en sus prerrogativas, sea porque los contribuyentes consideran que la presión a que se les somete es excesiva, o bien debido a que algún colectivo entiende que no está obligado a responder a la demanda concejil, surgen en ocasiones las resistencias, que algunas veces desembocan en conflictos y pleitos.

Como es bien conocido, una parte del vecindario queda exento del pago de ciertos tributos en orden a su condición social: se trata de los privilegiados, que gozan de esa situación debido a su estatuto nobiliar, a alguna merced real expresa, o a su condición clerical. Aunque tales privilegios pueden provocar la protesta o la resistencia del resto de los contribuyentes, en líneas generales la situación es aceptada, siempre que no se produzcan cambios, cuando se trata de impuestos ordinarios; pero no sucede lo mismo con la fiscalidad extraordinaria, en especial la indirecta. En el caso de la sisa, los concejos entienden que todos deben contribuir, de manera que procuran no hacer distinciones ${ }^{67}$. Dado que es frecuente que los tributos extraordinarios sean impuestos para atender los

${ }^{64}$ Denis Menjot, Fiscalidad y sociedad.Los murcianos y el impuesto en la Baja Edad Media, p. 63 .

${ }^{65}$ Isabel Montes Romero-Camacho, "El abastecimiento de agua a la Sevilla bajomedieval: los moros cañeros y el acueducto de los Caños de Carmona", en Beatriz Arízaga Bolumburu y Jesús Á. Solórzano Telechea, Construir la ciudad en la Edad Media, Logroño, 2010, p. 55-90.

${ }^{66}$ Hipólito Rafael Oliva Herrer, La Tierra de Campos a fines de la Edad Media. Economía, sociedad y acción política campesina, Valladolid, 2002, p. 365. Cristina Segura Graíño, "Los oficios del agua", en $\mathrm{M}^{\mathrm{a}}$ Isabel del Val Valdivieso (coord.), Vivir del agua en las ciudades medievales, Valladolid, 2006, p. 37-38.

${ }^{67}$ Esta es una tendencia general que también se observa en otras áreas, véase por ejemplo José Hinojosa Montalvo y Juan Antonio Barrio Barrio, "Las sisas en la gobernación de Orihuela durante la Baja Edad Media", Anuario de Estudios Medievales, 22, 1992, p. 545. 
gastos de las obras públicas, y debido a que parte de éstas están relacionadas con el agua, esas resistencias afectan en ocasiones al tema que nos ocupa.

Cuando un concejo actúa de esa forma, quienes protestan contra las sisas son aquellos que se consideran exentos por su condición, en particular los clérigos, que cuentan, además, con una organización que les permite presentar un frente común, así como con un arma poderosa con la que amenazar en caso de necesidad, el entredicho y la excomunión. Este tipo de conflictos concejo-clérigos es relativamente frecuente, cuando los primeros, aquejados por la urgencia de obtener los fondos necesarios para atender a las nuevas necesidades, pretenden incrementar el número de contribuyentes, mientras los clérigos defienden con firmeza su privilegio de exención. En general suele llegarse a acuerdos entre las partes, como sucede en los concejos riojanos de Logroño, Santo Domingo de la Calzada y $\mathrm{Haro}^{68}$, pero en otras ocasiones la tensión se mantiene y se amenaza con severas penas a la parte clerical.

Así reacciona el clero de la diócesis de Cartagena, respaldado por su obispo, quien en el sínodo celebrado en 1475 se ocupa del asunto ${ }^{69}$, por considerar que las exigencias de contribuir en las imposiciones y sisas para la realización de ciertas obras, entre las que se encuentran algunas relacionadas con el agua, en concreto "puentes e fuentes", suponen un abuso y un atropello a sus derechos consolidados. Todo el texto del obispo es muy expresivo al respecto. Comienza con una queja general contra los legos, quienes

no contentos con su poderíos fuerranse (esfuérzanse) en lo vedado e sueltan sus frenos a las cosas que a ellos no pertenescen. Et no parando mientes quanto les sea devedado el poderio en los clerigos e personas ecclesiasticas e en los bienes dellos contra la ecclesiastica libertad demandanles pechos e collectas e facenles pagar en las imposiciones e sisas que echan en la carne, pan, vino e otras viandas, paño, ropas e joyas e otras qualesquier cosas, bien assí como si los clerigos e personas ecclesiasticas e sus bienes fuessen de su jurisdiction.

Denuncia a continuación el motivo por el que se les somete a tal demanda:

Et por dar escusacion a sus pecados dicen que lo fasen para muros, puentes e fuentes o por los bienes realengos que poseen. Et aun facen sobrello ordinaciones e statutos e sfuerzanse en quanto pueden por

${ }^{68}$ Francisco Javier Goicolea Julián, "Finanzas concejiles en la Castilla Medieval: El ejemplo de la Rioja Alta", p. 46-47.

${ }^{69}$ Jorge Ortuño Molina (Edición y estudio), Sínodo de la diócesis de Cartagena (1475), Murcia, 2002, p. 143-145. 
diversas e muchas maneras de someter la clerecia e sus bienes a servidumbre e ponerla so su jurisdiction.

Y aún mantiene su queja cuando el concejo cede en parte en su pretensión, ya que lo que quieren es lograr una exención total:

Et quando mucho son apremiados sobre las dichas impusiciones dicen que daran viandas, ropas e las otras cosas francas solamente para los clerigos e personas ecclesiasticas, mas non para los que viven con ellos a sus despensas continamente.

Tras esta exposición general, el obispo considera inaceptables las pretensiones concejiles, máxime cuando alguno de los clérigos

aviendo miedo do no es de aver, amando la paz del mundo que es passadera e temiendo mas ofender a los señores temporales que a Dios, en tales abusaciones nesciamente e mala consienten no aviendo para ello special licencia de su prelado, el qual no la puede dar buenamente sin el Papa.

Para remediar la situación, "e aviendo intencion de quitar a los seglares tan fea usanza de poderio", decide el señor obispo, con el respaldo del sínodo, prohibir el pago de tales tributos a todos los eclesiásticos. Además, previendo que las autoridades concejiles no van a aceptar tal decisión de buena gana, toma medidas disuasorias, ya que establece que en el caso de que los concejos persistieran en la actitud de pedir a los clérigos su contribución en los supuestos indicados, el arcipreste o el vicario debería requerir "a los officiales de los lugares do tales pechos, collectas o impusiciones fueren puestas o statuto o statutos fechos", a ellos personalmente si puede reunirlos, y si no en la misa mayor, para que sea público y no puedan alegar desconocimiento; el objetivo de esa acción es ordenarles que en un plazo de seis días "revoquen e ayan revocado efectualmente los dichos pechos e imposiciones, sisas, statuto o statutos en quanto a los clerigos e personas ecclesiasticas e sus domesticos e continuos comensales, en tal manera que non paguen en ello cosa alguna". En caso de que no obedecieran, los oficiales y quienes les hubieran dado ayuda serían denunciados "publicamente por descomulgados" y el lugar puesto en entredicho, "fasta tanto que revoquen efetualmente los dichos pechos, collectas, imposiciones, sisas o statutos en quanto a ellos atañe e ayan satisfecho a los clerigos enteramente e personas ecclesiasticas de todo lo que pagaron".

Junto a las diferencias entre las administraciones eclesiástica y concejil, hay también enfrentamientos entre concejos. En estos casos los motivos de 
resistencia suelen girar en torno a la actuación de uno de ellos, que provoca la desconfianza y el enojo de otro, por considerar que la acción del primero hace peligrar alguna de las fuentes de ingreso del segundo. Eso es lo que sucede en torno a la construcción de un puente sobre el río Najerilla en los años finales del siglo XV. Nájera, teme que una parte importante del tráfico decida atravesar la corriente por el paso que está construyendo el concejo de Arenzana de Yuso, y por lo tanto que sus ingresos por el pontazgo que exige a las mercancías que pasan por el puente de su jurisdicción se vean seriamente reducidos; por esta razón protesta ante el Consejo Real, en un intento por defender lo que entiende que es su exclusivo derecho; pero constatando que su protesta no tiene un efecto inmediato, acaban por derribar el nuevo puente, construido en madera, lo que obliga a los reyes a intervenir a través del corregidor de Logroño ${ }^{70}$. Precisamente esta ciudad protagoniza a su vez un enfrentamiento con varios concejos vecinos por el uso del agua del Ebro para el riego ${ }^{71}$.

Y, por supuesto, se producen resistencias de los contribuyentes frente a las exigencias concejiles de tributos directos extraordinarios, lo que a veces da lugar a conflictos. En 1452, para reparar los desperfectos provocados por una inundación en el azud y las acequias, el concejo de Murcia impone, a los regantes, molinos, batanes y tintes, una taja proporcional a las tandas de riego y tahullas; en 1456 exige otra taja para reparar el azud que de nuevo había sido dañado por una riada el año anterior; pero el impuesto no se cobra bien, ya que en el verano de 1456 el concejo no había ingresado todavía el fruto de la primera imposición, ni en 1458 lo resultante de la segunda ${ }^{72}$. En Logroño, una derrama impuesta en 1493, cuyo fruto iba destinado a favorecer a los regadíos con el agua del río Asa, provocó la protesta de algunos vecinos, que consideraban que la autoridad local había actuado de forma arbitraria ${ }^{73}$.

\section{Conclusión}

El agua se presenta por lo tanto como un elemento estrechamente relacionado con la fiscalidad concejil, y con la actuación de los regimientos en el ejercicio

${ }^{70}$ Francisco Javier Goicolea Julián, "Finanzas concejiles en la Castilla Medieval: El ejemplo de la Rioja Alta", p. 29.

${ }^{71}$ Margarita Cantera Montenegro, "Pleitos por términos del concejo de Logroño (1475-1495)", Berceo, 108-109, 1985, p. 72-75.

${ }^{72} \mathrm{M}^{\mathrm{a}}$ del Carmen Veas Arteseros, Fiscalidad concejil en la Murcia de fines del medievo, p. $187-190$.

${ }^{73}$ Margarita Cantera Montenegro, "La hacienda concejil y la vida económica en Logroño en tiempos de los Reyes Católicos (1475-1495)”, p. 514. 
de sus funciones como gobierno urbano. En ocasiones es utilizada por los reyes para intervenir en la vida de villas y ciudades. Es un elemento que permite el embellecimiento del núcleo, que los vecinos cuenten con más comodidades (agua próxima al domicilio), y que la ciudad esté mejor dotada, y por lo tanto que sea más honrada. Pero para el concejo es también una fuente de renta, directamente mediante la cesión de su uso, o indirectamente a través de instalaciones particulares o bienes de propios como los puentes o los molinos. Y es un motivo de gasto, derivado de su aprovechamiento. 